Supplement of

\title{
A new method for operating a continuous flow diffusion chamber to investigate immersion freezing: assessment and performance study \\ Gourihar Kulkarni et al.
}

Correspondence to: Gourihar Kulkarni (Gourihar.Kulkarni@pnnl.gov) 

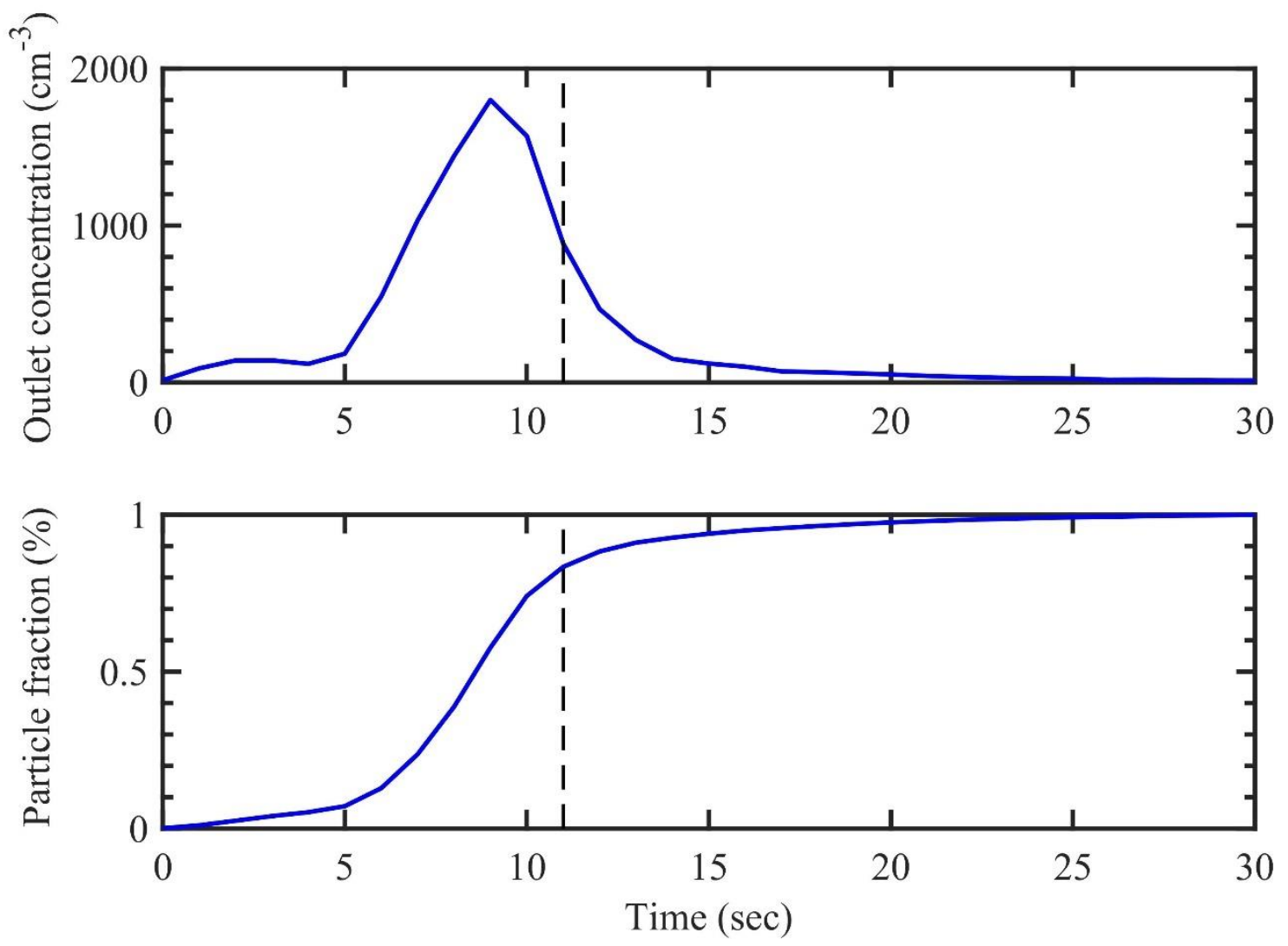

Figure S1: Measured particle concentration and corresponding particle fraction at the outlet of the ice chamber during particle pulse experiments. The data from three particle pulse experiments were averaged. The vertical dashed line indicates the duration of the particle pulse, and the particles that are measured after this dashed line are classified to be moved out of the aerosol lamina. 
a)

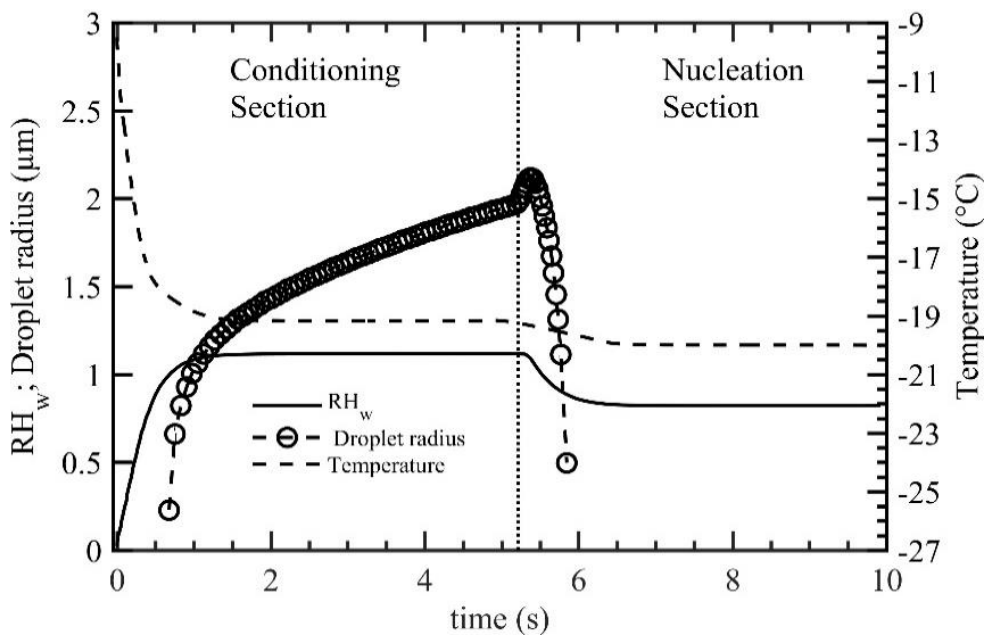

b)

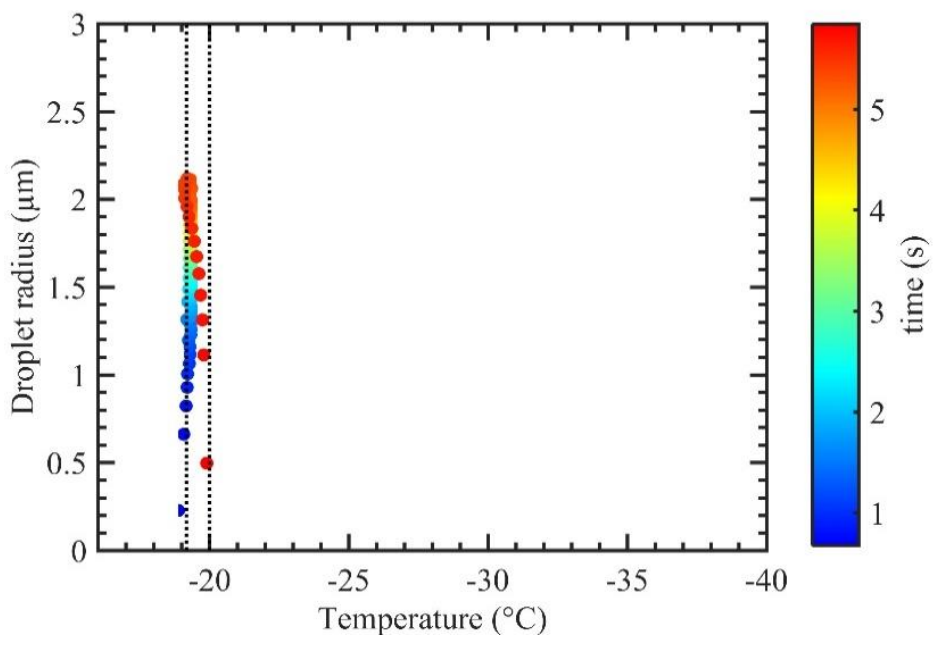

c)

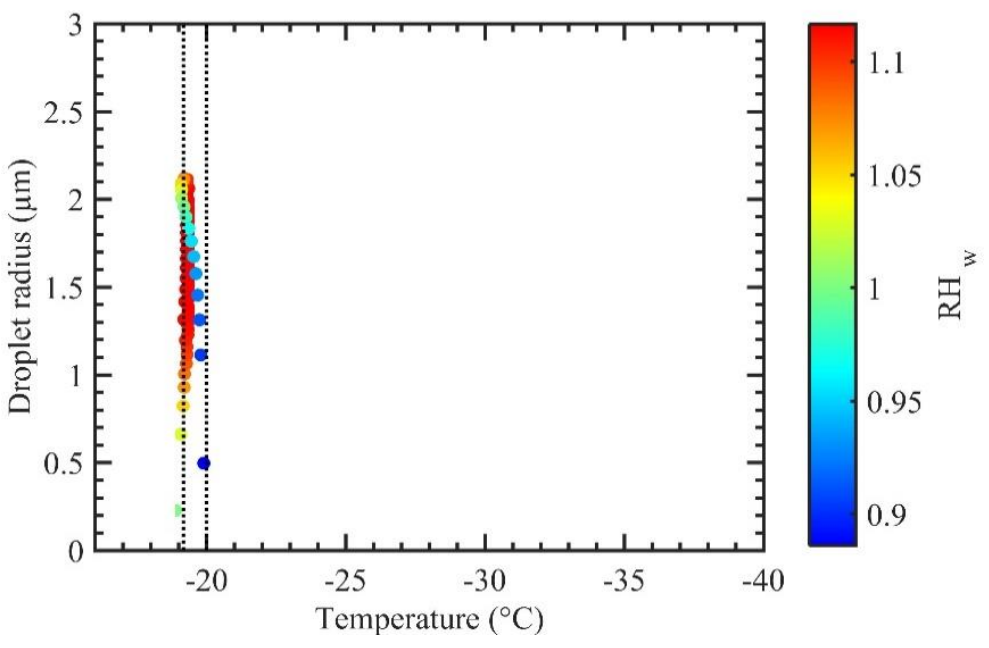


Figure S2: (a) CFD calculated temperature and $\boldsymbol{R H}_{w}$ profiles of a potential INP released from the sample injection region to the outlet end of the chamber. The warm and cold walls of conditioning section are maintained at -9 and $-27^{\circ} \mathrm{C}$, respectively. The nucleation section is maintained at $-20^{\circ} \mathrm{C}$. Analytical calculations of droplet growth and evaporation of such a potential INP $(0.3 \mu \mathrm{m}$ in diameter) are also shown. The left and right side of the vertical dotted line represent the conditioning and nucleation sections, respectively. (b) and (c) Alternative representation of similar data shown in panel (a) except as a function of $\boldsymbol{R H}_{w}$ and time, respectively. The two vertical dotted lines represent the aerosol lamina temperature $55\left(\sim-19.7^{\circ} \mathrm{C}\right)$ and nucleation section temperature $\left(-20^{\circ} \mathrm{C}\right)$. Droplets grow for $\sim 5 \mathrm{~s}$ to $\sim 4 \mu \mathrm{m}$ in diameter. Within the nucleation section, these droplets are subjected to colder temperatures than the aerosol lamina temperature and are evaporated. 
a)

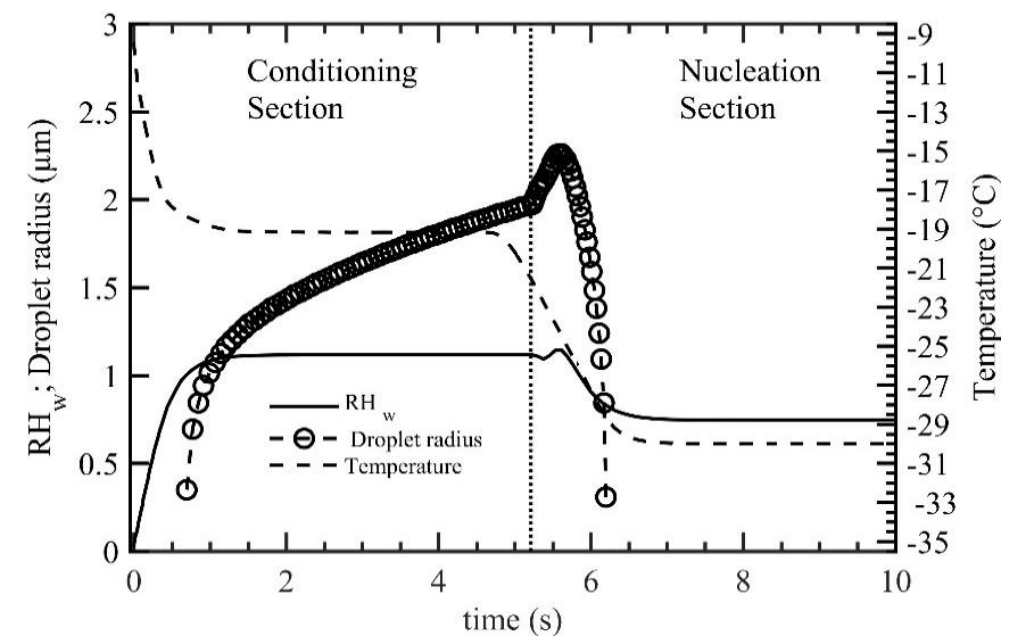

b)

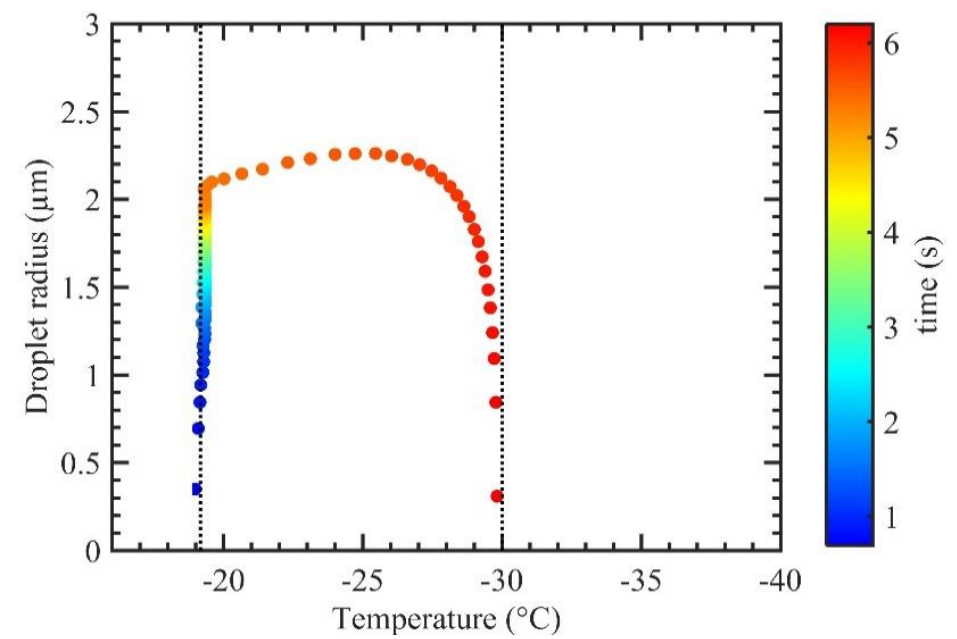

c)

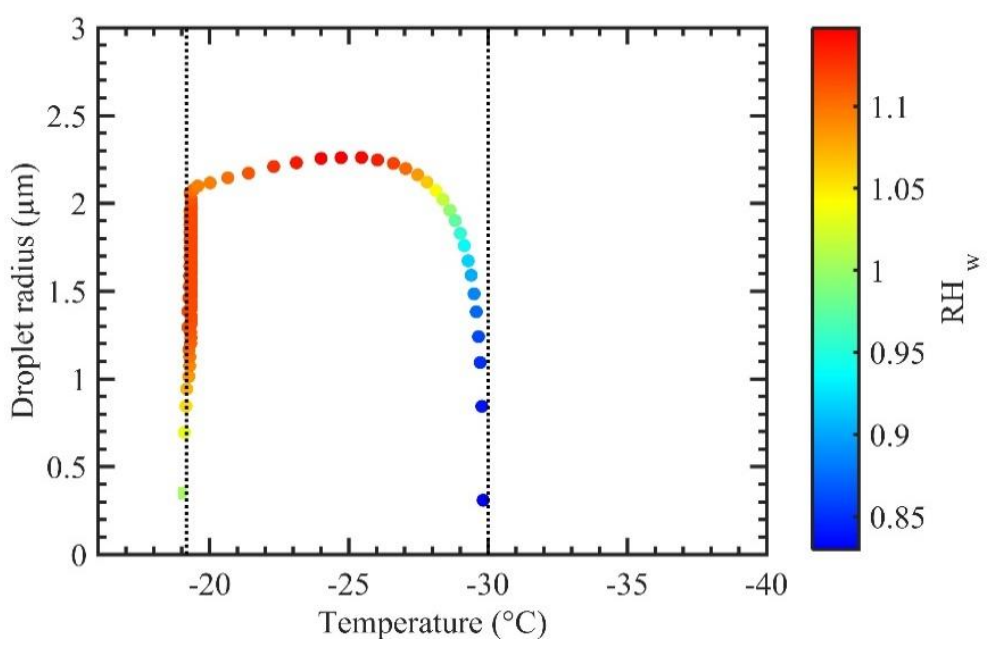

Figure S3: As in Fig. S2, but nucleation section is maintained at $-30^{\circ} \mathrm{C}$. 
a)

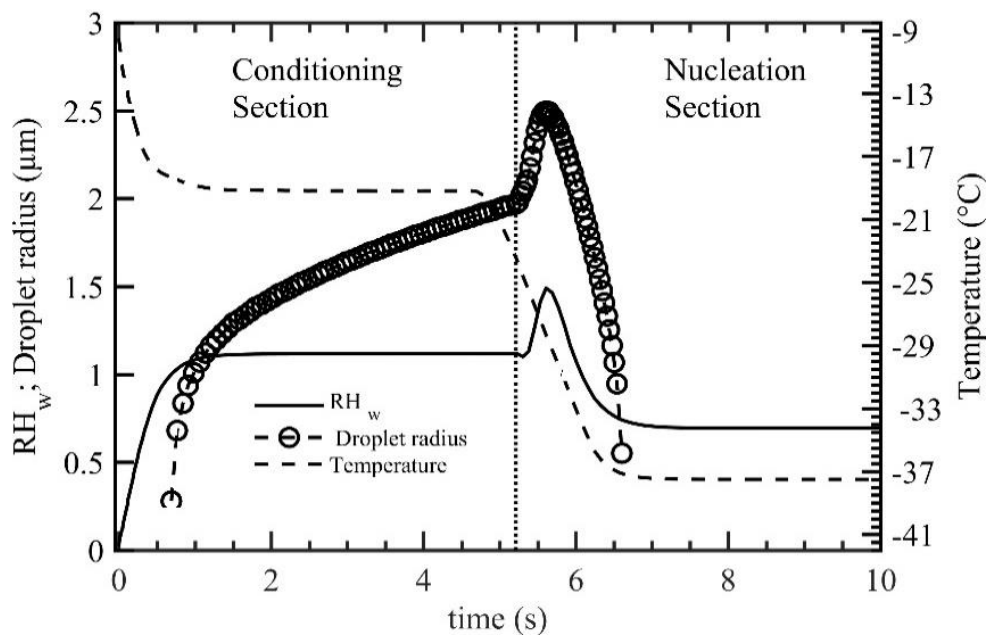

b)

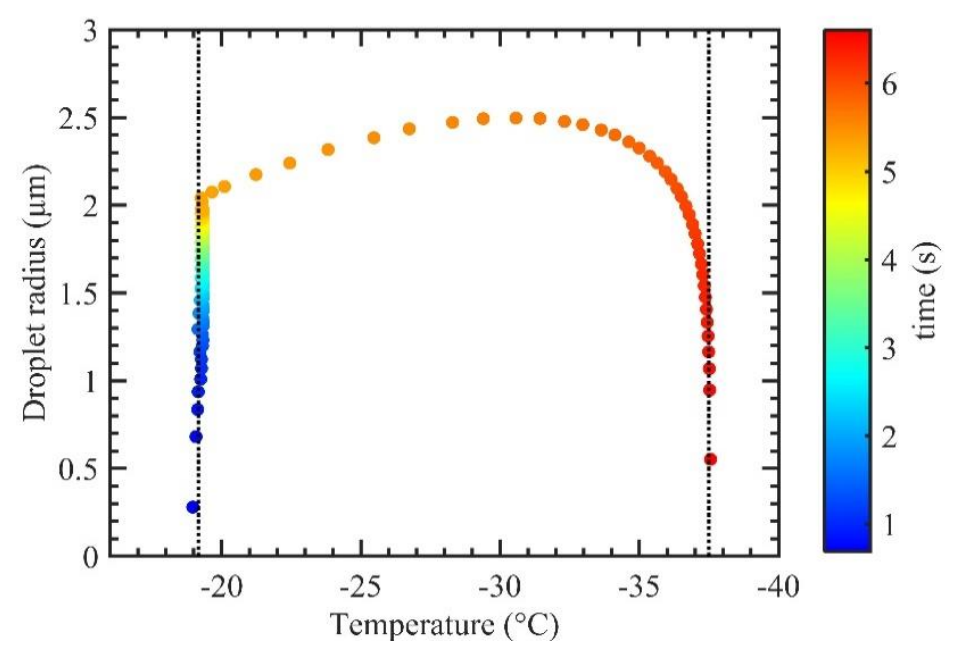

c)

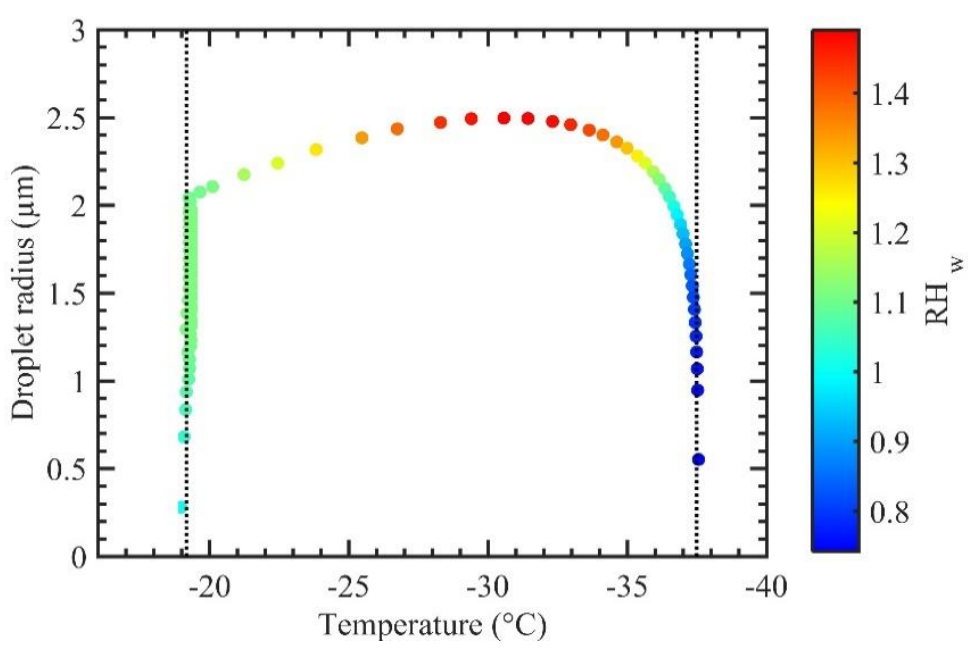

Figure S4: As in Fig. S2, but nucleation section is maintained at $-37.5^{\circ} \mathrm{C}$. 
a)

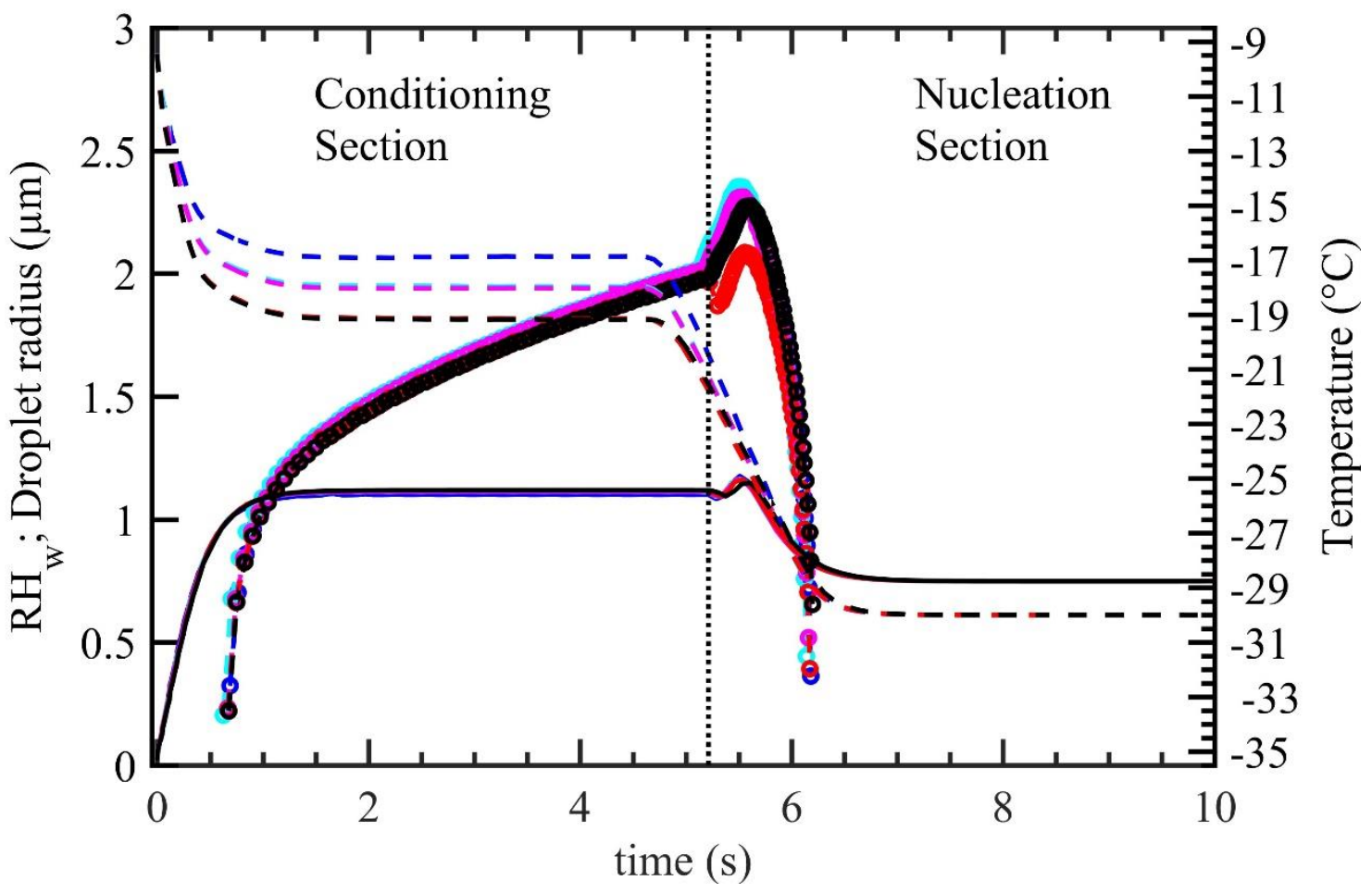

b)

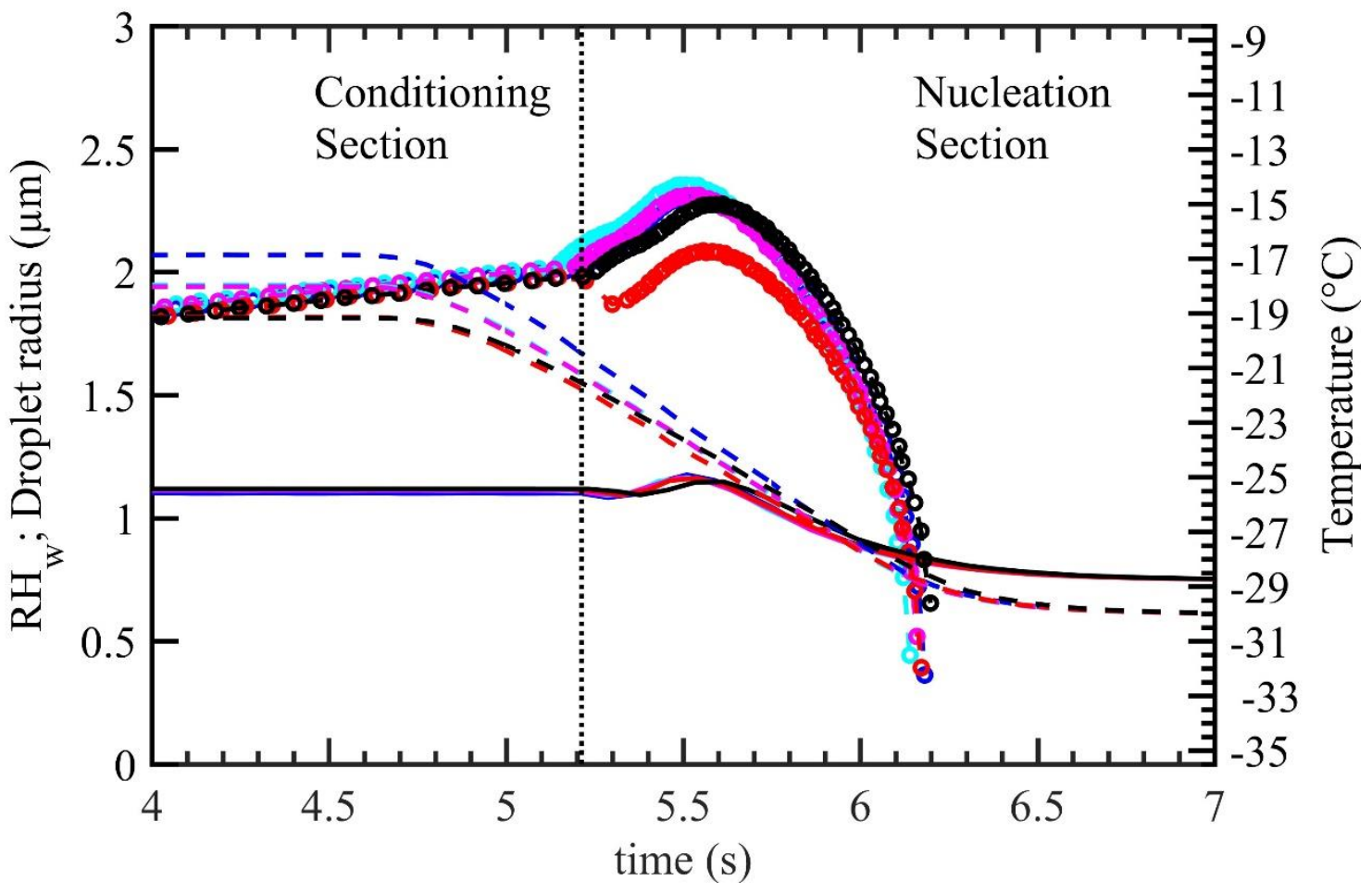

Figure S5: (a) As in Fig. S3 (a), but data from the five potential INPs. The source positions of these INPs are chosen such that they represent all the particles that are released from the inlet section of the chamber. The black, red, pink, teal, and blue INP trajectories are released 4.35, 4.425, 4.5, 4.575, and 4.65mm distance away from the cold wall (see Figure 3 for more details). The black color trajectory is also shown in Fig. S3 (a). (b) Enlarged view of a junction where both conditioning 
and nucleation sections meet. The INPs are exposed to range of temperature conditions $\left(-17\right.$ to $\left.-19.5^{\circ} \mathrm{C}\right)$ within the conditioning section but converge to a single temperature after $\sim 0.5 \mathrm{~s}$ on entering the nucleation section. Such spread in the temperature distribution however does not affect the droplet evaporation kinetics as they all evaporate within $\sim 1 \mathrm{~s}$ after they enter the nucleation section. 


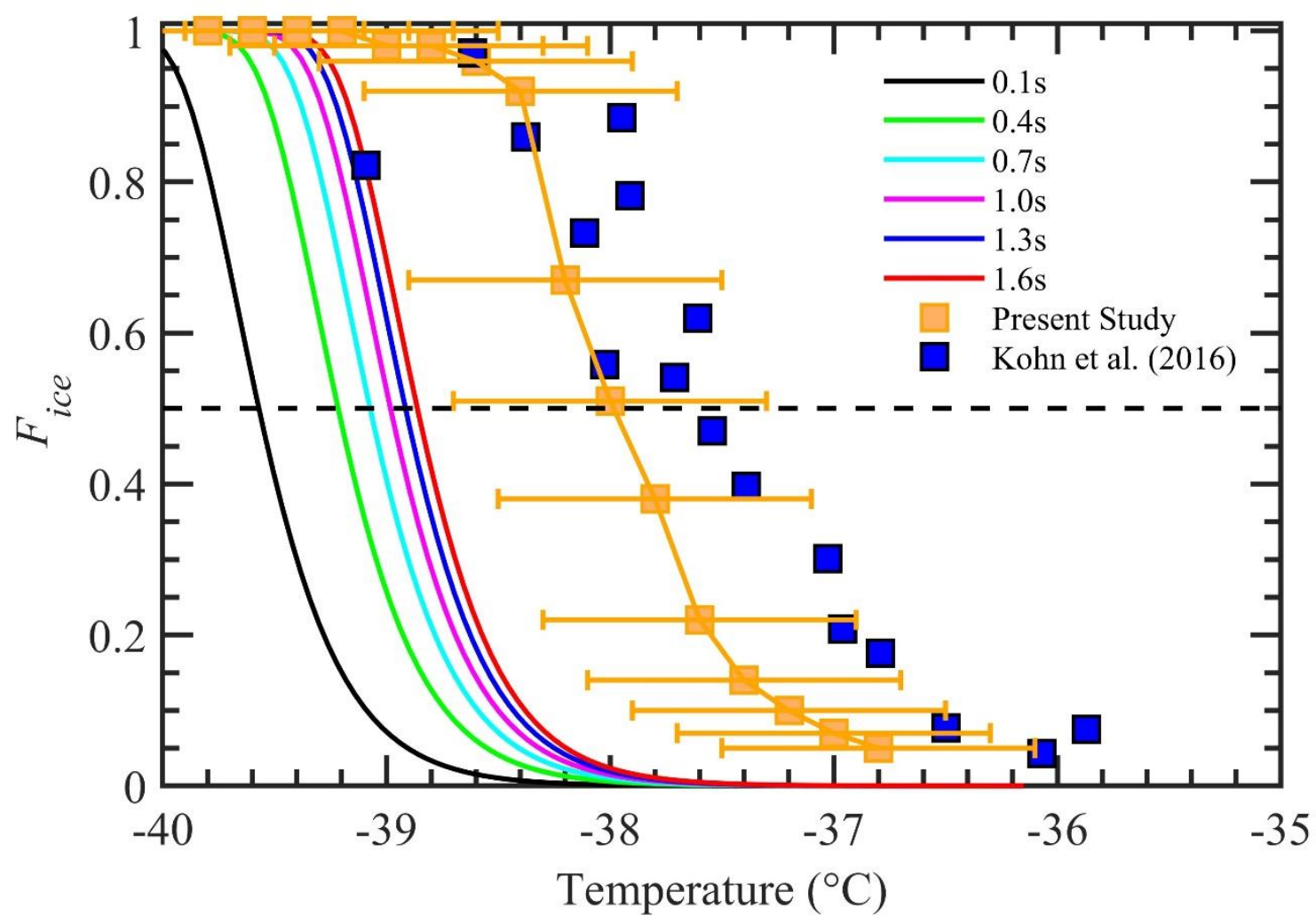

Figures S6: The theoretical frozen fraction curves of the droplets of diameter $4 \mu \mathrm{m}$ as a function of probable droplet residence time within the nucleation section. The calculations are based on the homogenous nucleation rate reported previously by other studies, see text for details. Square markers indicate the experimental results from this and previous study (Kohn et al. 2016). Future studies can be employed to extend these calculations to smaller droplets. 
a)
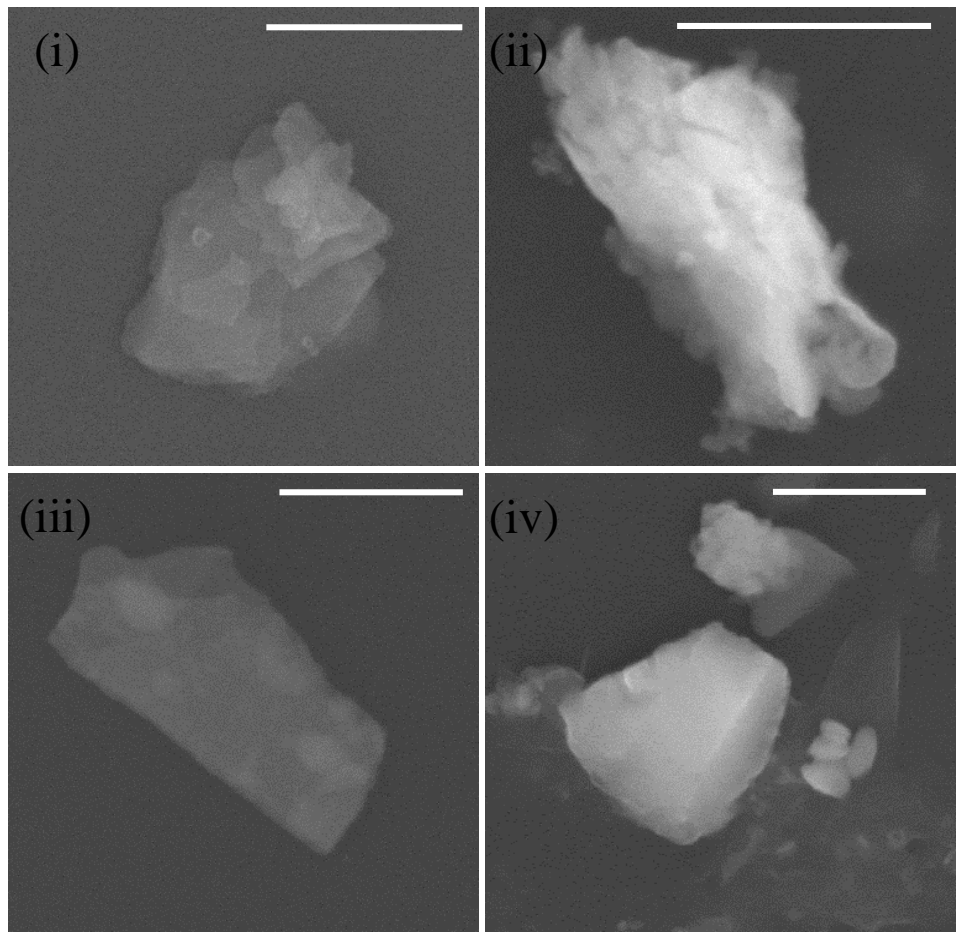

125

b)

130
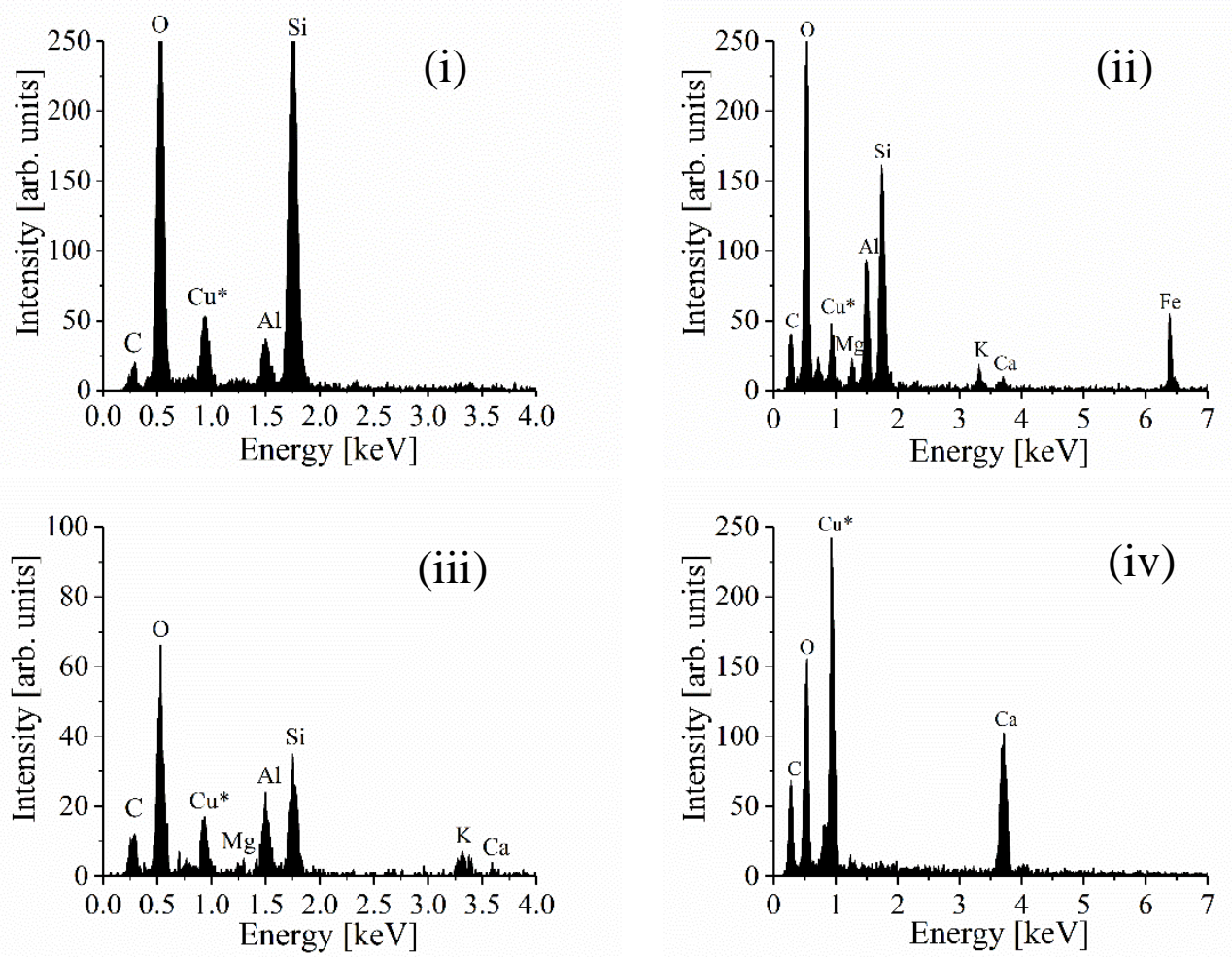
c)

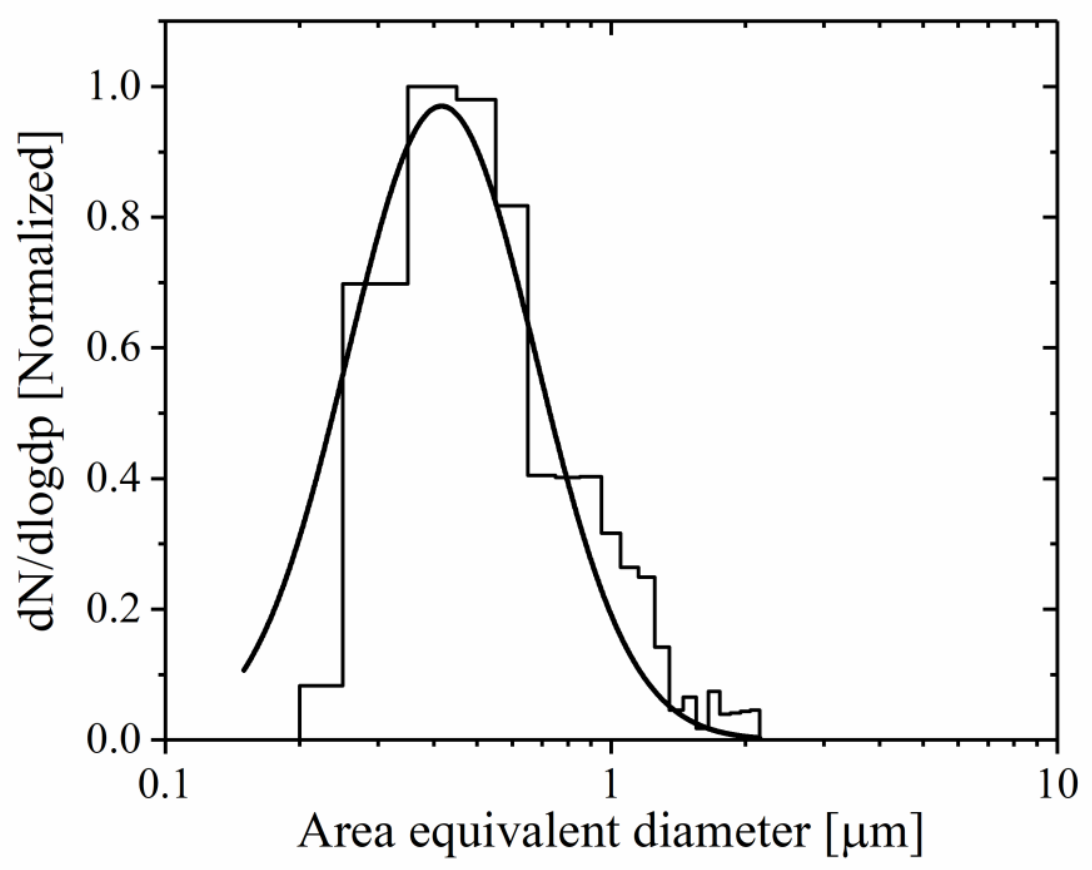

d)

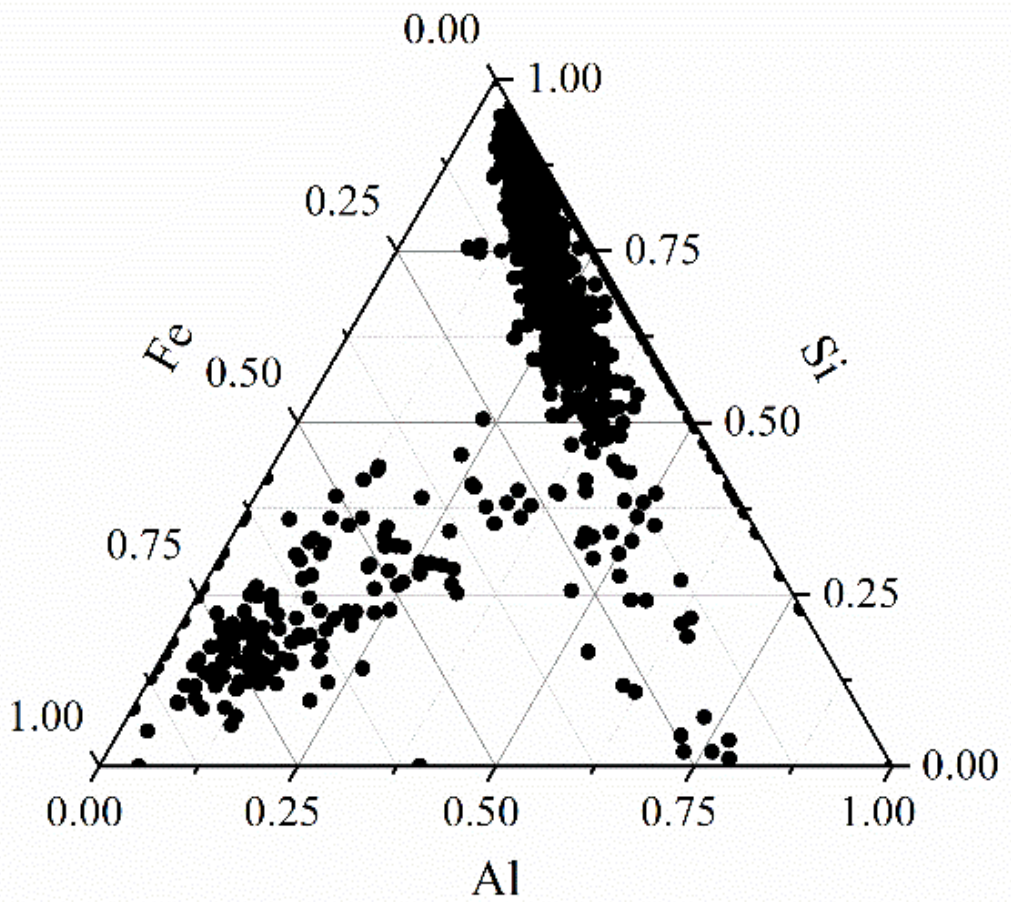


170 Figure S7: Morphology (a), elemental composition (b), size distribution (c), and ternary diagram (d) of airborne desert dust particles sampled at PNNL location. The particle size distribution with a lognormal fit $(0.53 \pm 0.02 \mu \mathrm{m})$ was obtained after analysis of total 1183 particles. Ternary plot of $\mathrm{Al}, \mathrm{Si}$, and $\mathrm{Fe}$ components of dust particles suggest two distinct types: $\mathrm{Si}$ rich and Fe-rich dust particle. The white bar in (a) represents the scale equal to $1 \mu \mathrm{m}$.

175 


\section{S.1 Droplet growth and evaporation calculations}

The droplet growth and evaporation calculations are performed using a water vapor diffusion growth theory (Rogers and Yau, 1988) that neglects temperature corrections and kinetic and ventilation effects as follows:

$$
\frac{d m}{d t}=4 \pi r D_{v}\left(\frac{e_{\infty}}{R_{v} T_{\infty}}-\frac{e_{r}}{R_{v} T_{r}}\right)
$$

205

where

$m=$ mass of the droplet $(\mathrm{kg})$;

$t=$ time $(\mathrm{s})$

$r=$ radius of the droplet $(\mathrm{m})$;

$D_{v}=$ diffusion coefficient of water vapor in air $\left(\mathrm{cm}^{2} \mathrm{~s}^{-1}\right)$ at environment temperature $(T$ in $\mathrm{K})$ and environment pressure ( $p$ in $\mathrm{mb}$ ) is given by,

$$
D_{v}=0.211\left(\frac{T}{273.15}\right)^{1.94}\left(\frac{1013.25}{p}\right)
$$

$e_{\infty}$ and $e_{r}=$ environment and equilibrium water vapor pressure (Pa), respectively;

$R_{v}=$ gas constant for a unit mass of water vapor $\left(\mathrm{J} \mathrm{K}^{-1} \mathrm{~kg}^{-1}\right)$;

$215 T_{\infty}$ and $T_{r}=$ environment and droplet surface temperature (K), respectively.

Equation (1) can be solved to obtain the final radius ( $r_{l}$ in $\mathrm{m}$ ) of the droplet as follows:

$$
r_{1}=\left(\frac{3}{\rho} r_{0} D_{v}\left(\frac{e_{\infty}}{R_{v} T_{\infty}}-\frac{e_{r}}{R_{v} T_{r}}\right) t+r_{0}^{3}\right)^{1 / 3}
$$




\section{S.2 Ice fraction calculations}

The ice fraction $\left(F_{i c e}\right)$ as function of temperature $(T)$ is calculated as follows:

$$
F_{i c e}(T)=\frac{N_{i c e}(T)}{N_{t o t}}
$$

230

where, $N_{\text {ice }}(T)$ is the cumulative number of frozen droplets between conditioning section temperature $\left(\sim-20^{\circ} \mathrm{C}\right)$ and set temperature of the nucleation section, and $N_{\text {tot }}$ is the total number of droplets that enter the nucleation section. 
Table S1: The evaporative cooling of an individual droplet of $4 \mu \mathrm{m}$ in diameter cooled at different temperature and humidity conditions. The maximum supercooling of the droplet $\left(=0.26{ }^{\circ} \mathrm{C}\right)$ is observed at $-20{ }^{\circ} \mathrm{C}$ and a saturation ratio of 0.8 . The cooling is very small $(<0.001)$ for certain temperatures at $\boldsymbol{R H}_{w}=0.99$.

\begin{tabular}{c|ccc}
\hline \multirow{3}{*}{\begin{tabular}{c} 
Ambient Temperature \\
\cline { 2 - 4 }$\left({ }^{\circ} \mathrm{C}\right)$
\end{tabular}} & \multicolumn{3}{|c}{ Evaporative cooling $\left({ }^{\circ} \mathrm{C}\right)$} \\
\hline-20 & 0.99 & Ambient saturation ratio & 0.8 \\
\hline-30 & 0.01 & 0.9 & 0.26 \\
-40 & very small & 0.12 & 0.11 \\
\hline
\end{tabular}

